\title{
Zebra finches show spatial avoidance of near but not far distance traffic noise
}

\author{
Quanxiao Liu *, Hans Slabbekoorn and Katharina Riebel \\ Institute of Biology, Leiden University, Sylviusweg 72, 2333 BE Leiden, The Netherlands \\ *Corresponding author's e-mail address: q.liu@ biology.leidenuniv.nl
}

Received 16 June 2019; initial decision 7 August 2019; revised 13 February 2020; accepted 21 February 2020; published online 4 March 2020

\begin{abstract}
Traffic noise is on the rise worldwide. Birds have been reported to decrease in number and diversity near highways. This could be indirectly caused by traffic if birds avoid overall poorer habitat quality near highways or directly if birds actively avoid noisy conditions. To test whether traffic noise directly affects birds' spatial preferences, we designed a preference test where zebra finches (Taeniopygia guttata) could move freely between noisy and quiet aviaries that only differed in the type of noise playbacks. During playback of high amplitude traffic noise recorded near from highways $(5-15 \mathrm{~m})$, birds spent significantly more time in the quieter aviary. Such spatial preferences were not observed during playbacks of moderate amplitude traffic noise recorded further away (200-400 m). Our result provides experimental support for the growing notion that traffic noise itself rather than the presence of vehicles may suffice to deter birds from busy roads.
\end{abstract}

\section{Keywords}

anthropogenic noise, traffic noise, birds, noise avoidance behaviour, two-choice set-up, Taeniopygia guttata.

\section{Introduction}

Anthropogenic noise continues to increase worldwide and traffic noise has now become the most prominent source of noise pollution (Barber et al., 2010; Mennitt et al., 2015). This is of great concern as chronic exposure to traffic noise has been found to be associated with physiological stress, sleep disturbance, hearing deficits and suboptimal cognitive performance in humans (Basner et al., 2014; WHO, 2017). In the EU alone, 28 million citizens are thought to suffer health effects from chronic noise exposure (Nugent et 
al., 2014). Traffic noise is affecting more and more rural areas, including national parks and conservation zones, and there is increasing concern that this may negatively affect wildlife (Barber et al., 2011; Iglesias Merchan et al., 2014). An increasing number of field studies have now reported declining diversity and abundance of animals near roads (reviewed by Newport et al., 2014) a phenomenon especially well documented in birds (Reijnen et al., 1996; Bayne et al., 2008; Francis et al., 2009; Parris \& Schneider, 2009; Benítez-López et al., 2010; Arévalo \& Newhard, 2011; Goodwin \& Shriver, 2011; Herrera-Montes \& Aide, 2011; Proppe et al., 2013).

Declines in animal populations near roads could come about by several different mechanisms directly or indirectly affecting fitness. High noise levels can trigger physiological and behavioural stress responses (Wright et al., 2007; Kight \& Swaddle, 2011; Shannon et al., 2016; Injaian et al., 2018a, b, 2019; Kleist et al., 2018). Traffic noise can mask acoustic signals and undermine their reception, as demonstrated in avian (Grade \& Sieving, 2016), anuran (Tennessen et al., 2014), fish (Vasconcelos et al., 2007) and invertebrate (Bent et al., 2018) species. Impaired communication could affect attraction to a particular site, mate attraction and/or survival. Although some species have been observed to partly compensate the effects of low-frequency masking noise by singing or calling at higher frequency or amplitude, or adjusting when to produce sounds (Brumm \& Slabbekoorn, 2005; Parks et al., 2011; Derryberry et al., 2016; Luther et al., 2016), these changes can compromise signal quality and functionality (Halfwerk et al., 2011a; Huet des Aunay et al., 2014). Increased noise levels have also been found to be associated with reduced foraging performance and predator avoidance in birds (Ware et al., 2015; Grade \& Sieving, 2016), but also in other taxa, for example, in bats (Siemers \& Schaub, 2011), fish (Voellmy et al., 2014) and crustaceans (Wale et al., 2013; Hubert et al., 2018). Any of these reported effects of noise exposure on acoustic signals could potentially affect individual fitness and reproductive success. In line with this, within-population comparisons have revealed that birds breeding in relatively noisy territories can have reduced pairing success (Habib et al., 2007), smaller clutch sizes (Halfwerk et al., 2011b), reduced parental care (Naguib, 2013) and smaller and lighter fledglings (Kight et al., 2012; Kleist et al., 2018) compared to birds in more quiet territories.

However, observations of noise-related patterns of reduced breeding performances do not necessarily reveal the underlying processes. Reduced 
breeding performance near roads could also arise if these territories are of lower quality because of chemical pollution, the presence and movement of cars and different vegetation (Reijnen et al., 1996; Summers et al., 2011; Jack et al., 2015), and/or if these territories are more likely to be occupied by lower quality individuals (e.g. first time breeders) unable to secure better quality territories further away from roads (Injaian et al., 2018c). Moreover, noise does not always reduce bird abundance: Francis et al. (2009) investigated noise impact on community composition at gas well exploitation sites and found that noisy sites had fewer predator species than quiet sites, but that the total number of birds did not differ between sites. Accordingly, some species were more abundant, presumably because of reduced predation pressure. These observations suggest species differences in sensitivity to noise, but also that next to direct effects of noise, additional indirect effects can arise through species interactions. Such ecological complexity can make it difficult to identify which mechanisms underlie noise-associated distributions. Experimental studies are required to test whether the noise itself or other factors associated with the actual noise sources (e.g. chemical pollution, presence of moving machinery or vehicles) deter birds from noisy territories (Francis et al., 2009; Slabbekoorn \& Halfwerk, 2009; Halfwerk et al., 2011b; Hubert et al., 2018).

Experimental approaches, for example using noise playbacks in the field, allow excluding traffic associated factors other than noise. Using such an approach, Blickley et al. (2012) found that playbacks of sound recordings of oil drilling activity and heavy vehicle traffic reduced lek attendance of greater sage-grouse (Centrocercus urophasianus) at playback versus control sites. McClure et al. (2013) constructed a 'phantom road' - a line of loudspeakers placed in trees playing back road noise at a known migratory stop-over site in a nature reserve. In alternating blocks of four days with and without road noise playbacks, the total number of individuals using the stopover site was significantly lower during days with road noise playbacks. This experiment convincingly demonstrated an impact of road noise (rather than the road itself) on the usage of a migratory stop-over site. However, for both of the aforementioned field playback studies different mechanisms could have been underlying the reductions in birds attending the sites: the noise itself could have kept the birds away and/or the noise masked the vocalizations of the birds already on site and thereby prevented the phonotactic aggregation 
of more birds (Mönkkönen \& Forsman, 2002; Winger et al., 2019), a phenomenon that has been demonstrated experimentally (Schepers \& Proppe, 2017).

To test whether noise becomes so aversive that it affects spatial preferences requires testing paradigms that allow individuals to choose among identical locations only differing in noise characteristics as well as suitable model species. Domesticated zebra finches and other related estrildid finches have already been successfully studied in experiments investigating the effect of masking noise on their vocal communication (Cynx et al., 1998; Tumer \& Brainard, 2007; Potvin \& MacDougall-Shackleton, 2015; Villain et al., 2016; Tachibana et al., 2017). These studies, however, passively exposed birds to noise without offering quiet(er) alternative spaces. To the best of our knowledge, only one bird study offered birds to move between different noise levels (Evans et al., 2018), while testing the masking effect of noise on foraging behaviour. In this study, high level noise affected individuals' vigilance during foraging, but not their spatial choices: Birds were not observed to move from louder to more quiet foraging chambers after having entered either one of them. In this set-up, entering a chamber enabled the individually tested subjects of this social species not only to feed but also to come physically closer to sounds of conspecifics. Perhaps the birds stayed on because of these factors that were not tested separately but only in conjunction with the noise. Several other studies in other taxa also tested for noise avoidance, but generally did not provide choices between otherwise identical locations (see Table 4). However, we could identify one study that offered animals identical spaces only differing in the amount of noise. Schaub et al. (2008), tested mouse-eared bats (Myotis myotis) foraging forays from a central space into two identical chambers differing in the level of noise playback and found that the bats preferentially and more successfully foraged in the quieter space. Birds have not yet been tested in controlled experimental exposure studies that explicitly compared avoidance of different types of traffic noise in favour of quieter locations.

In the study presented here, we opted for a two-choice set-up offering two options that were identical but for the type or absence of noise. This with the aim to test if birds would always avoid highway noise in favour of quieter locations or whether such behaviour was dependent on the type of noise (in this case highway noise recorded at different distances). In our set-up, small groups of adult zebra finches could move freely between two interconnected 
aviaries: one with the relatively quiet ambient laboratory sound level and one with highway noise playbacks recorded at either near or far distances. If (highway) noise per se is aversive to birds, we expect birds to show active avoidance of noise by moving to and spending more time in quiet than noisy compartments during highway noise playbacks.

\section{Material and methods}

\subsection{Subjects and housing}

Test subjects were adult domesticated zebra finches (32 males, $778 \pm 58$ days old; 32 females, $739 \pm 76$ days old) from an outbred breeding colony at Leiden University. Prior to testing, birds had either been housed in aviaries or cages of different sizes (width $\times$ depth $\times$ height ranging from $80 \times 40 \times$ $40 \mathrm{~cm}$ to $170 \times 80 \times 200 \mathrm{~cm})$. All birds were moved into the same type of aviaries $(170 \times 80 \times 200 \mathrm{~cm})$ at least one week prior to experiments. Each of these holding aviaries housed only males or only females (group size 4-16 individuals). All housing and testing rooms had a light regime of 14:10 h light: dark with 15 min of light fading in and out at the start and end of the light period. The temperature was kept between $20-22^{\circ} \mathrm{C}$ and humidity between 35 and 50\%. Birds had ad libitum access to water, mixed seeds (Deli Nature, Beyers, Schoten, Belgium), grit and cuttlefish bone. This daily diet was complemented twice a week with egg food, fresh fruit and vegetables and once a week with germinated seeds. All birds were marked with a numbered orange colour ring (Hayes, UK) on their right leg.

\subsection{Experimental set-up: two-choice aviaries}

In the testing room, two identical aviaries of equal size $(200 \times 200 \times$ $200 \mathrm{~cm})$ were interconnected by a wire mesh tunnel $(100 \times 50 \times 50 \mathrm{~cm}$, see Figure 1). Each aviary contained one loudspeaker (CB4500, Blaupunkt, Hildesheim, Germany) placed at $1 \mathrm{~m}$ height in the corner the furthest away from the tunnel and a webcam (HD Pro C920, Logitech, Lausanne, Switzerland) at the top of the corner facing the tunnel. In each aviary there were four parallel perches perpendicular to the tunnel and a fifth parallel perch in the tunnel (see Figure 1). All side walls with the exception of the tunnel were covered with $3 \mathrm{~cm}$ thick sound attenuating material. Food and water dispensers were suspended underneath the two outermost perches, providing ad libitum access to food and water in both aviaries. The connecting tunnel 


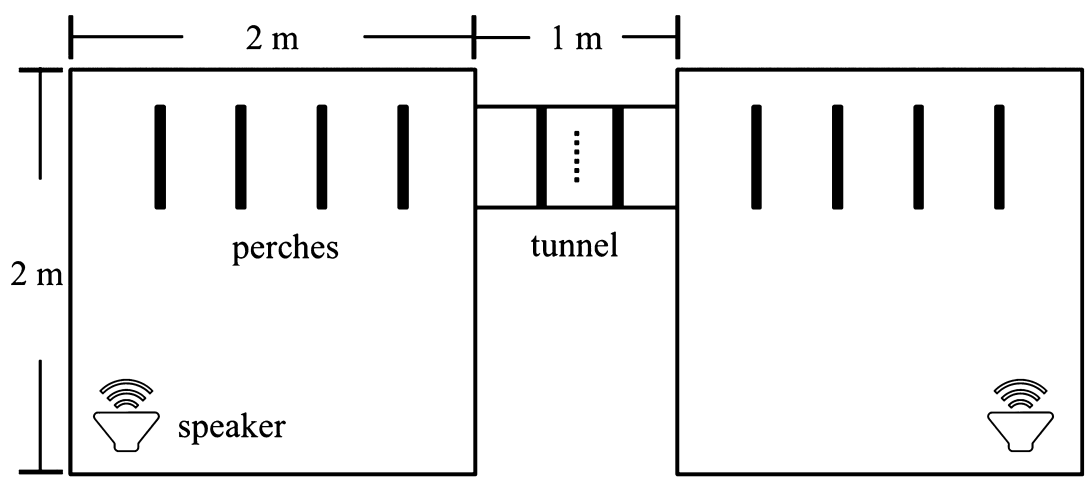

Figure 1. Top view of the experimental set-up. Two aviaries were interconnected by a tunnel with a central wire mesh partition with a small opening $(30 \times 30 \mathrm{~cm})$ surrounded by a rectangular shaped antenna of the same size (dashed line) that automatically read the ID's of each passing bird's electronic tag. Thick black lines indicate perches $(50 \mathrm{~cm}$ long, $12 \mathrm{~mm}$ in diameter). Each aviary contained a loudspeaker (speaker symbol) on a 1-m tripod.

had an entrance $(50 \times 50 \mathrm{~cm})$ at each end that could be opened and closed remotely by operating a wire mesh trap door. A wire mesh separator $(50 \times$ $50 \mathrm{~cm}$ ) in the middle of the tunnel could be passed only via a smaller opening of $30 \times 30 \mathrm{~cm}$ surrounded by a black metal antenna (ANTSER300, Dorset, Aalten, The Netherlands) which was connected to a PC outside the room and registered the ID of the tags of passing birds.

\subsection{Highway noise recordings and playback design}

Continuous 24-h recordings (44 $100 \mathrm{~Hz}$ sampling rate, 32 bits, waveform audio file format) of highway traffic noise were made between 5 July 2017 and 10 August 2018 using two song meters (Model SM1, Wildlife Acoustics, Maynard, MA, USA). Recordings from four different sites in the Netherlands were used for this experiment: (1) Vlietland $52^{\circ} 06^{\prime} 12.5^{\prime \prime} \mathrm{N} 4^{\circ} 26^{\prime} 28.1^{\prime \prime} \mathrm{E}$, (2) Polderpark Cronesteyn $52^{\circ} 08^{\prime} 12.9^{\prime \prime} \mathrm{N}$ $4^{\circ} 30^{\prime} 07.5^{\prime \prime} \mathrm{E}$, (3) Oegstgeest $52^{\circ} 10^{\prime} 34.2^{\prime \prime} \mathrm{N} 4^{\circ} 27^{\prime} 33.4^{\prime \prime} \mathrm{E}$ and (4) Park Landskroon, $52^{\circ} 10^{\prime} 22.7^{\prime \prime} \mathrm{N} 4^{\circ} 27^{\prime} 07.6^{\prime \prime} \mathrm{E}$. At each site, two song meters were fixed to trees or shrubs in such a way that the microphone pointed in an uninterrupted line across open pasture to the highway. One sound meter was always placed at a far (200-400 m) and one at near $(5-15 \mathrm{~m})$ distance to the highway to then record near and far highway noise for a continuous period of $24 \mathrm{~h}$. This resulted in four sets of matched recordings where each set had been recorded simultaneously at the same site but at two different distances 
from the same highway. Before starting each recording (between 1030 and 1200 h), a sound pressure meter (Model 30, Pulsar Instruments, Filey, UK; mode: A-weighted, LAT reading at $30 \mathrm{~s}$ intervals, re: $20 \mu \mathrm{Pa}$ ) was positioned $2 \mathrm{~cm}$ above the sound meter microphone and pointed in the same direction. Absolute sound pressure levels were then measured at 30-s intervals for at least $2 \mathrm{~min}$ as the A-weighted equivalent continuous sound level (LAeq). With these measures the LAeq of the remainder of the entire 24-h recordings were calculated using 30-s bins. The medians of these bins (in $\mathrm{dB}(\mathrm{A})$ ) for locations 1-4 for the near distance recordings were 68.7, 68.7, 69.9, 71.6 and for the far distance recordings were 53.2, 52.6 55.3, 55.3.

From each of these eight 24-h recordings, the hour from 11 to 12 am (to avoid rush hours) was selected for further processing and stimulus preparation. Each of these one-hour recordings was split into 0.02-s bins. For these bins, the decibels relative to full scale were obtained by assigning the level of $0 \mathrm{~dB}$ FS to the maximum digital level in the recording and then scaling the remainder of the recording to this maximum using the 'to intensity' function in Praat (v. 6.04.40, Boersma \& Weenink, 2019) that squares and convolves the sound values with a Gaussian analysis window of $0.02 \mathrm{~s}$. The bin values were transferred to the statistical software R (v. 3.4.1, R Core Team, 2019) to search and flag all time stamps with extremely high amplitudes ( $>2$ standard deviations, i.e., louder than $97.5 \%$ of all 0.02 bins). Using the Audacity(R) (v. 2.1.2; Audacity Team, 2019) acoustic software (v. 2.1.2) the flagged passages were inspected acoustically and visually (by QL). This revealed that these extreme amplitudes always occurred when, in addition to the highway noise, other sudden onset sounds had been picked up by the microphone such as car honking or dogs barking or the noise of low overflying aircraft. Sudden sounds easily startle birds (and make them fly away); to prevent this we edited out these extreme amplitude sounds so that they could not confound or exacerbate highway noise avoidance. The editing consisted of deleting the bin associated with the event using the 'delete' function in Audacity. Overall, this procedure removed only 90 s per 3600-s-long sound file. After this step, the recordings were checked in their entirety again while listening to the recordings via headphones (by QL) which confirmed that the above procedure had removed all sudden onset sounds. Next, 30 continuous minutes from each of the 8 recordings were selected by using a random number generator to pick a number between 0 and 28 and then using this number as the minute to start the extraction of the subsequent $30 \mathrm{~min}$ as stimuli. 
As final editing step, the first and last two minutes of each 30-min stimulus were faded in and out in Audacity. Generally, the near-distance highway noise recordings were much louder than those recorded at far distances and because of frequency-dependent degradation, far distance recording differed in aspects of spectral composition from the near distance recordings (see Figure 2). Next to these overall differences, we need to point out that all recordings were real time non-stop field recordings and both recording categories had transient biotic and abiotic sound sources that added stochastic variation akin to what a wild animal would experience in a 30 -min period next to roads.

For playbacks, stimulus amplitude at the 4th perch (the most distant from the tunnel) was set to match the sound level at the original recording locations using the same sound pressure level meter as described above. After the adjustment, we also took sound pressure level measures during the noise playbacks at all other perches. Peak noise levels within the aviary decreased from the 1st perch (furthest from the speaker and closest to the tunnel) to the 4th perch (nearest to the speaker) and ranged from $45-55 \mathrm{~dB}(\mathrm{~A})$ during playbacks of the far-distance highway recordings to $55-75 \mathrm{~dB}(\mathrm{~A})$ during playbacks of the near-distance highway recordings. With either playback on in one aviary, noise levels in the quiet aviary without playback ranged from 35-40 dB(A). To put these measures into perspective: Zebra finches generally experience sound levels of $46-68 \mathrm{~dB}(\mathrm{~A})$ in our breeding rooms and background noise in natural habitats is estimated to range from $35-75 \mathrm{~dB}(\mathrm{Z})$ on windy days (Villain et al., 2016). Note in this context that decibel is measured on a log scale, and doubles in intensity every $6 \mathrm{~dB}$, so the differences between ambient and either of the two highway noises were in the order of one to several magnitudes but the absolute maximum levels of $75 \mathrm{~dB}(\mathrm{~A})$ were far from the level (approx. $100 \mathrm{~dB}(\mathrm{~A})$ ) where hearing and auditory

Figure 2. Power spectra (left column) and spectrograms (centre and right columns) of all near- and far- distance highway noise stimuli. Each pair of stimuli was recorded from two different distances at one of four different locations (GPS details see Table A1 in the Appendix). The power spectra show the decibels relative to full scale (dB FS) at $0-5 \mathrm{kHz}$. The spectrograms show the power spectral density (PSD). Relative sound pressure levels are indicated by the colour gradient. All plots were calculated using the entire $30 \mathrm{~min}$ of each stimulus (R package PAMGuide, Hamming window, 1s resolution, 0-5 kHz, 50\% window overlap; data averaging: Welch method set as 5, following the recommendations by Merchant et al., 2015). 
Power spectrum/RMS

\section{Spectrogram}

Near

Far

Site I near highway $A 4$
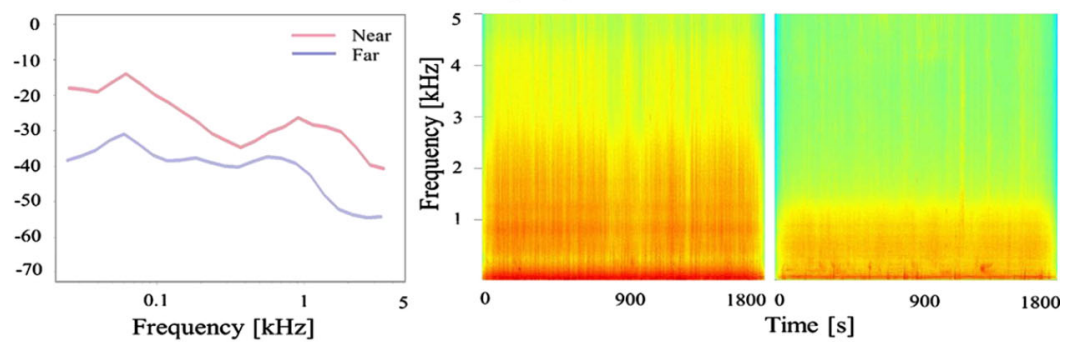

Site 2 near highway A4
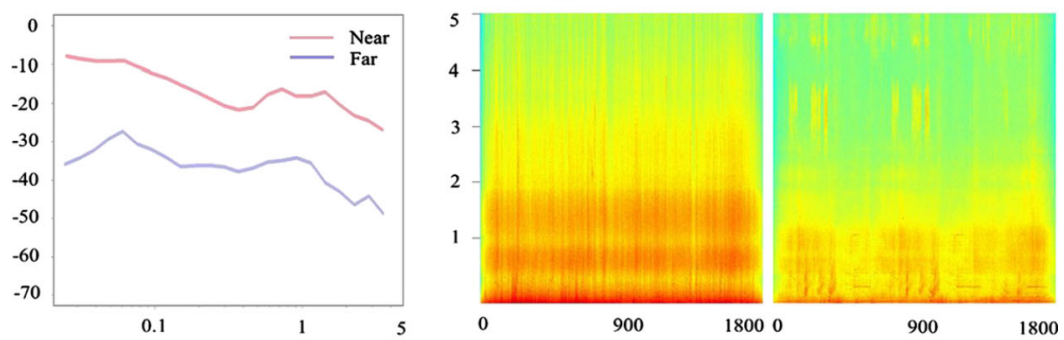

Site 3 near highway A44
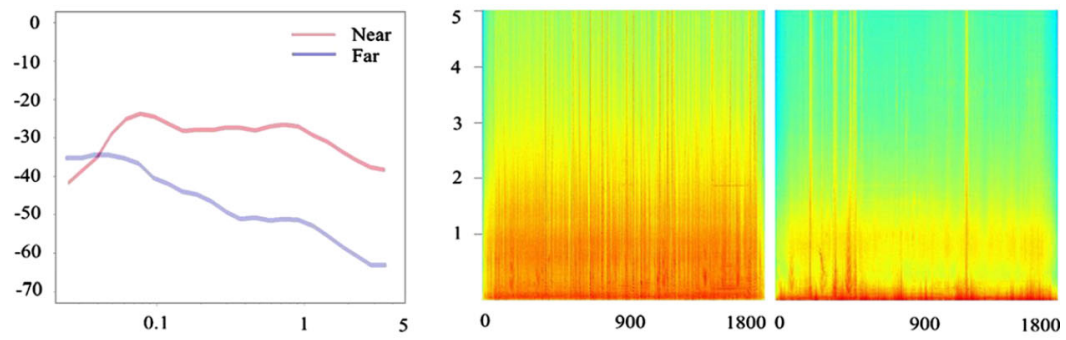

Site 4 near highway $A 44$
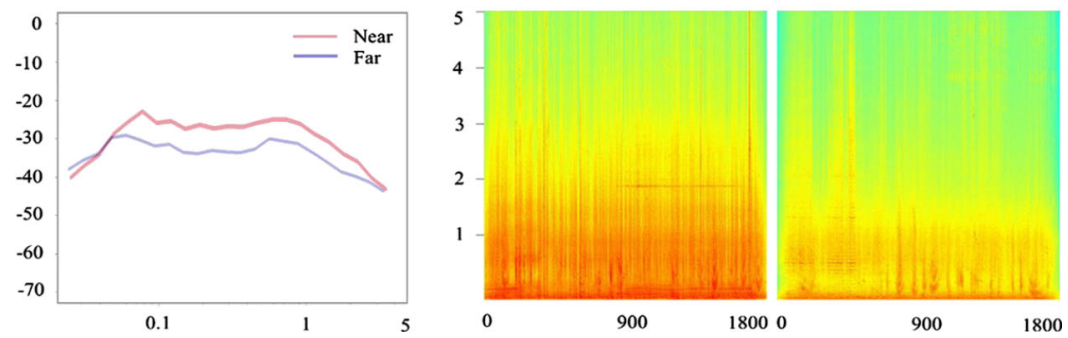
feedback are blocked and way below the thresholds for hearing damage in zebra finches (Funabiki \& Konishi, 2003; Zevin et al., 2004). The playback levels however fall into the range of background noise that has been found to affect parameters of acoustic communication in zebra finches (Cynx et al., 1998; Villain et al., 2016).

\subsection{Playback trials}

Zebra finches are highly social (Zann, 1996) and explore new environments faster in groups than when alone (Coleman \& Mellgren, 1994; Schuett \& Dall, 2009). Because zebra finches prefer being in groups and birds had to be moved into a new room for testing, we aimed to reduce neophobia by testing birds in small groups (consisting either of four males or four females). Birds were gently caught from their home aviaries the day before a playback test (19 $\pm 2 \mathrm{~h}$ before the first playback) and each bird was fitted with a small plastic leg ring with a micro transponder tag (ID100A, Dorset). Birds were then released into the central tunnel connecting the two experimental aviaries. At this stage, the trap doors at either end were closed and were not opened until after a short delay of about $5 \mathrm{~min}$. This was the time it took the experimenter to leave the experimental room to enter the adjacent observation chamber and to remotely open both trap doors from there. From the moment the trap doors at either end of the tunnel were opened, birds could freely move and explore both aviaries. The next morning, at around $10: 00 \mathrm{~h}( \pm 90 \mathrm{~min})$ the data $\log$ of the antenna readings was checked and in all 16 tested groups, birds had crossed the tunnel between the aviaries multiple times which was the criterion to start the first experimental playback.

There were three playback trials for each experimental group. The first two playbacks were fully balanced with respect to the order (near or far tested first against quiet) and whether aviary 1 or 2 was used for the first playback (for a schematic overview of the playback procedure see Figure 3c). Testing started by switching on both loudspeakers without playing back sound to register birds' baseline behaviour (pre-playback) for $15 \mathrm{~min}$. Then, the first 30-min playback started in one of the aviaries while the other remained quiet. After 30 min the playback stopped and then started in the other aviary for another $30 \mathrm{~min}$. Afterwards, there was a $15 \mathrm{~min}$ break without any playback which was followed by the second $2 \times 30$ min playback that now was either near- or far-distance highway noise (whichever sound had not yet been played back during the first trial). After the second playback another 


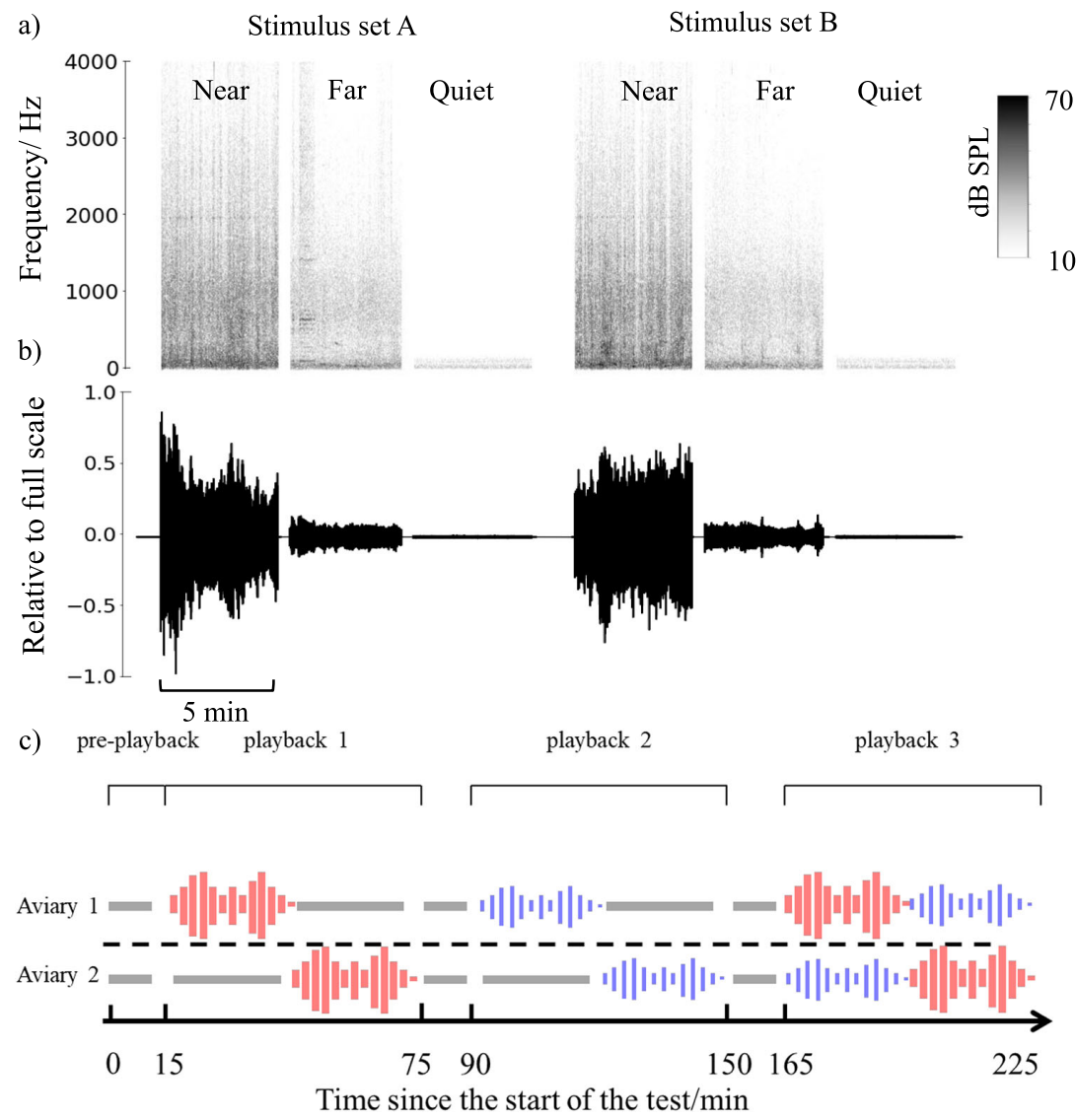

Figure 3. Highway noise stimuli and playback design: (a) Frequency spectrograms of 5 min of recordings in the experimental aviaries during the near- and far-distance highway noise and no playback ('quiet') condition. The spectrograms were computed by Fast Fourier Transformations (using scipy library in python 3.7, window length 4096 points, overlap 512 points, time step $0.08 \mathrm{~s}$, frequency step $11 \mathrm{~Hz}$ ). (b) Waveforms of the same stimulus sets ( $y$-axis: SPL to full scale). (c) Timeline: 15 min pre-playback (grey bars: no playback, but loudspeakers already switched on) were followed by a 30 min playback of traffic noise (red, near-; blue, fardistance highway noise) in one aviary and no playback in the other (quiet) aviary, followed by another $30 \mathrm{~min}$ after stimulus reversal. After a 15-min silent break, this procedure was repeated with the other noise category. After another 15-min break, playback 3 exposed the birds to simultaneous playback of the near- and far-distance highway noise for $30 \mathrm{~min}$. For illustration, the timeline shows only one presentation order (red, near-distance highway noise first), but presentation order was fully balanced and half the trials started with far distance noise first). 
15-min break followed before the third playback trial started, where nearand far-distance noise playback each started simultaneously in one of the two aviaries and then lasted for $30 \mathrm{~min}$. We fully balanced the aviary $\times$ stimulus type combinations and stimulus sets. However, due to a playback file error during playback 3 , four groups had to be excluded from the analyses of playback 3 .

To measure the time the birds spent in each aviary, all video recordings were analysed by the same observer (QL) using the BORIS video analysis software (v. 6.1.6, Friard \& Gamba, 2016) playing back the recordings at $3 \times$ normal speed. All videos were scored with the sound switched off so that the observer did not know which playback treatment the birds on the screen were experiencing. Videos were analysed by scoring 'the number of birds in aviary 1' as a single state event as follows: Whenever a bird passed from one aviary to the other via the small opening with the antenna in the middle of the tunnel, the video was paused and the state event was updated with the new number of birds in aviary 1 . If a bird stayed in the tunnel without passing through the antenna, the time spent in the tunnel counted toward the aviary on the same side. Sometimes, individual birds were sitting on the antenna for a while. In such cases, $50 \%$ of the duration of this event was added as 'time spent' to aviary 1 and the other $50 \%$ to aviary 2 . For each playback, the cumulative time spent by all birds in aviary 1 (from now on referred to as 'total time in aviary 1') was then calculated (multiplying the duration of each state event with the corresponding number of birds during this event). The maximum total time all four birds could spend in either aviary thus was $120 \mathrm{~min}$ (= 4 birds $\times 30$ min playback) and once aviary 1 was scored, time spent in aviary 2 could be calculated (120 min total time all birds - total time in aviary $1=$ total time aviary 2 ). Note that this means that for analyses, only one value per group was used, as the movements of the four birds in a group cannot be assumed to be independent of each other. Total time spent per aviary was then transformed to the relative proportion of time spent in either aviary; this parameter could range from 0 (no bird visited an aviary during playback) to 1 (all birds stayed in the same aviary for the whole duration of the playback).

\subsection{Ethical note}

The experiments described here were reviewed and approved by the committee for animal experimentation at Leiden University and the Centrale Commissie voor Dierproeven (CCD) of the Netherlands (permit 
AVD1060020171409), and monitored by the Animal Welfare Body of Leiden University, in accordance with national and European legislation.

\subsection{Analyses}

Prior to statistical analyses, the proportion of time spent in either aviary was calculated (time in aviary 1 or $2 /$ total time). Because proportional data tend to centre around the mean, all proportional data were arcsine square root transformed (Sokal \& Rohlf, 1995) prior to statistical analyses (but were back transformed for illustrations and reporting in the text).

To verify whether birds preferred one of the two aviaries independently of sound treatment, we first tested whether the proportion of time spent in the left aviary during the baseline observations deviated from chance level using a one-sample $t$-test.

For playbacks 1 and 2 (where a one-sample $t$-test would result in pseudoreplication of groups and stimuli), we used a mixed model approach (using lme4 in R) to first test whether the time spent in the quiet aviary deviated from chance level by subtracting 0.5 from the observed proportions and then testing whether the intercept of a mixed linear model with only random effects ('stimulus ID' and 'group ID') deviated significantly from 0 (Tables 1 and 2, Model A). Next, we asked whether a preference for the quiet aviary

\section{Table 1.}

Mixed linear models testing whether total time spent in the quiet aviary (per group) deviates from chance level.

\begin{tabular}{lrcrr}
\hline Model & Estimate & SE & $t$ & $p$ \\
\hline $\begin{array}{l}\text { Model A }{ }^{1}: \\
\quad \text { Intercept }\end{array}$ & 0.12 & 0.04 & -2.73 & 0.01 \\
$\quad$ Model B ${ }^{2}$ : Playback & & & & \\
$\quad$ Intercept & 0.20 & 0.05 & -4.27 & $<0.001$ \\
$\quad$ Playback: Far & -0.16 & 0.03 & 4.94 & $<0.001$ \\
Model C: Playback + sex & & & & \\
$\quad$ Intercept & 0.18 & 0.06 & -2.80 & 0.009 \\
$\quad$ Playback: Far & -0.16 & 0.03 & 4.94 & $<0.001$ \\
$\quad$ Sex: Male & 0.05 & 0.06 & -0.73 & 0.47 \\
\hline
\end{tabular}

Model A, null model; Model B, playback added as fixed factor; Model C, playback + sex as fixed factors.

${ }^{1}$ Group ID and stimulus ID are included in all models as random effect.

${ }^{2}$ Marginal and conditional $r^{2}$ are 0.25 and 0.68 for Model B. 
Table 2.

Parameters of Models A-C.

\begin{tabular}{lccc}
\hline Model & AICc & $\Delta$ AICc & Weight \\
\hline Model A & -15.9 & 7.6 & 0.02 \\
Model B & -23.5 & 0.0 & 0.94 \\
Model C & -17.1 & 6.4 & 0.04 \\
\hline
\end{tabular}

differed between noise treatments, by adding noise type as factor to the model (Tables 1 and 2, Model B). To explore whether there was a difference in response to noise playback between sexes, sex was added to Model B as fixed factor to create Model C (Tables 1 and 2, Model C).

While all previous analyses tested the groups' behaviour as a whole, we also ran an additional analysis checking whether the playback treatment affected whether individual birds were more likely to split from the group. To this end, we compared all events (and their duration) where a single individual was observed in an aviary with respectively near- or far-distance highway noise during playbacks 1 and 2 with a generalized mixed linear model, using a Poisson distribution, with the cumulative time individual birds were staying alone in a particular aviary as response variable, playback in that aviary as fixed (quiet/far/near) and the group ID as random effect (Table 3, Model D).

For playback 3, where near- and far- distance highway noise playbacks were presented simultaneously (resulting in one data point 'relative time spent in the relatively more quiet aviary' per tested group), we tested whether the proportion of time spent in the aviary with far-distance highway noise playback differed from chance level with a one-sample $t$-test.

Table 3.

Mixed linear model testing whether birds spent more time alone in the aviary with playback (Model D).

\begin{tabular}{|c|c|c|c|c|}
\hline Model D ${ }^{1}$ : Playback & Estimate & SE & $z$ & $p$ \\
\hline Intercept & 6.66 & 0.20 & 33.47 & $<0.001$ \\
\hline Playback: Far & -0.12 & 0.01 & -10.47 & $<0.001$ \\
\hline Playback: Quiet & -0.56 & 0.01 & -41.63 & $<0.001$ \\
\hline
\end{tabular}

${ }^{1}$ Marginal and conditional $r^{2}$ are 0.08 and 0.99 for Model D. 


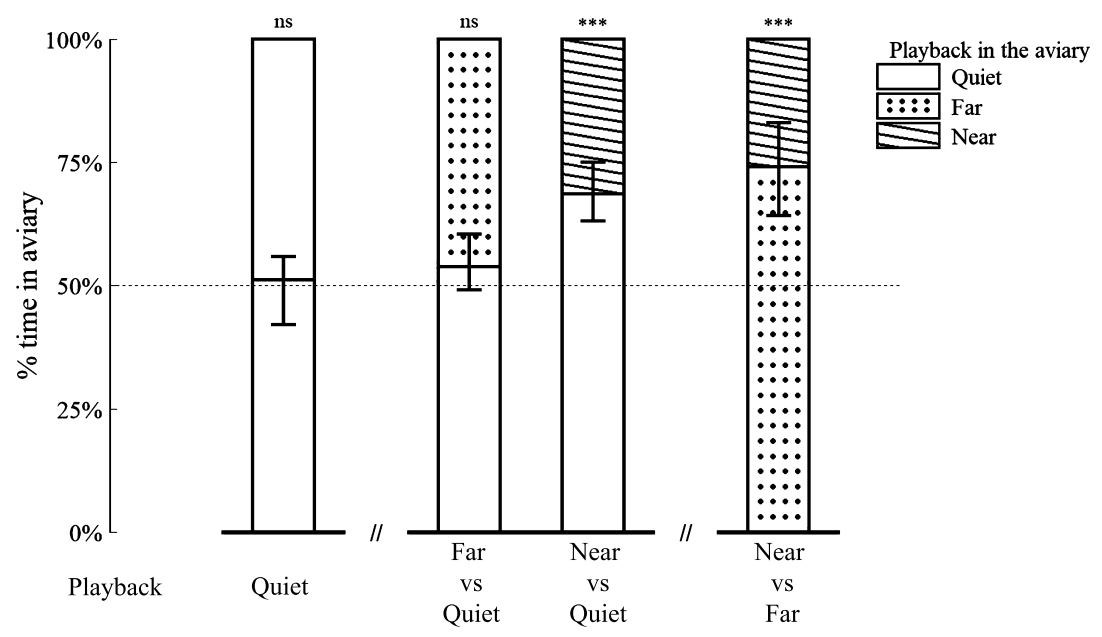

Figure 4. Time spent in the different aviaries during the different playback conditions. Bars show the percentage of time (mean $\pm 95 \% \mathrm{CI}$ ) groups spent in each of the two aviaries during the different playback conditions. Note that the values and their CIs are reciprocals within a playback condition. ${ }^{* * *}$ Significant, ns: not significant, see Tables 1 and 3.

\section{Results}

The different playback treatments affected how birds allocated their visiting time to the different aviaries (see Figure 4). In the absence of playback (during the 'pre-playback' phase) there was no difference in the amount of time birds spent in the left (or right) aviary (one-sample $t$-test: testing 'proportion of time spent in aviary 1 ' for deviation from a 0.5 chance level $\left.t_{15}=-0.34, p=0.74\right)$.

During playbacks 1 and 2, which offered the choice between a quiet (no playback) and a noisy aviary (playback of either near- or far- distance highway noise), birds spent more time in the quiet aviary, as evidenced by the significant deviation of the intercept from zero (Table 1, Model A). This effect was stronger for the near-distance noise; playback noise type (near or far) significantly affected the amount of time birds spent in the quiet aviary (Table 1, Model B). Comparing the proportion of time spent in the quiet aviary versus chance level for the two noise types separately, revealed a significant preference for the quiet aviary over the aviary with near-distance highway noise (one-sample $t$-test: $t_{15}=5.31, p<0.001$ ), but not over the far-distance highway noise (one-sample $t$-test: $t_{15}=1.33, p=0.20$ ). Males 
and females showed no difference in how they behaved in the tests (adding sex as additional factor did not improve the model see Table 1, Model C).

In addition, we also checked whether the birds' grouping behaviour was affected by the type of playback in a particular aviary by summing up all events where a single bird was alone in one of the aviaries. This revealed that the proportion of time a single bird was observed was slightly, but significantly higher in an aviary with near-distance noise than aviaries with either no or far-distance noise playbacks, but was overall very low during all conditions (median time single bird was observed: near $=972 \mathrm{~s}$, far $=733 \mathrm{~s}$ and no playback $=67 \mathrm{~s}$ out of a total of $14440 \mathrm{~s}$; see Table 3, Model D).

During playback 3, with near- and far-distance highway noise presented simultaneously, birds also spent less time in the aviary with the near-distance highway noise than expected by chance (deviation from 0.5 tested by a onesample $t$-test: $t_{11}=4.39, p=0.001$ ).

\section{Discussion}

The aim of our experiments was to test whether zebra finches would prefer quiet over noisy locations in an unconstrained choice situation. During the playback tests, birds could freely choose to move between two identical locations that only differed in their simulated soundscape (near- vs. fardistance highway noise). Birds did not avoid all noise playbacks but showed stimulus-dependent spatial preferences: they clearly avoided the near- but not the far-distance highway noise in favour of the quiet aviary.

Birds likewise avoided the near-distance highway noise during the simultaneous playbacks of near- and far-distance traffic noise. The combined observations from the sequential and simultaneous playbacks showed that the birds were showing stimulus-dependent avoidance (near-distance highway noise was avoided) rather than showing general avoidance or neophobic behaviour to a location with playback of (for them unknown) highway noise (far-distance highway noise was not avoided).

\subsection{Noise avoidance in the laboratory and in the field}

Our study adds to experimental work in other vertebrate taxa testing active noise avoidance (see Table 4). Only one of these studies — by testing bats allowed to hunt for prey in two identical free flight chambers (Schaub et al., 2008) - gave subjects a choice between two identical chambers only 
Q. Liu et al. / Behaviour 157 (2020) 333-362

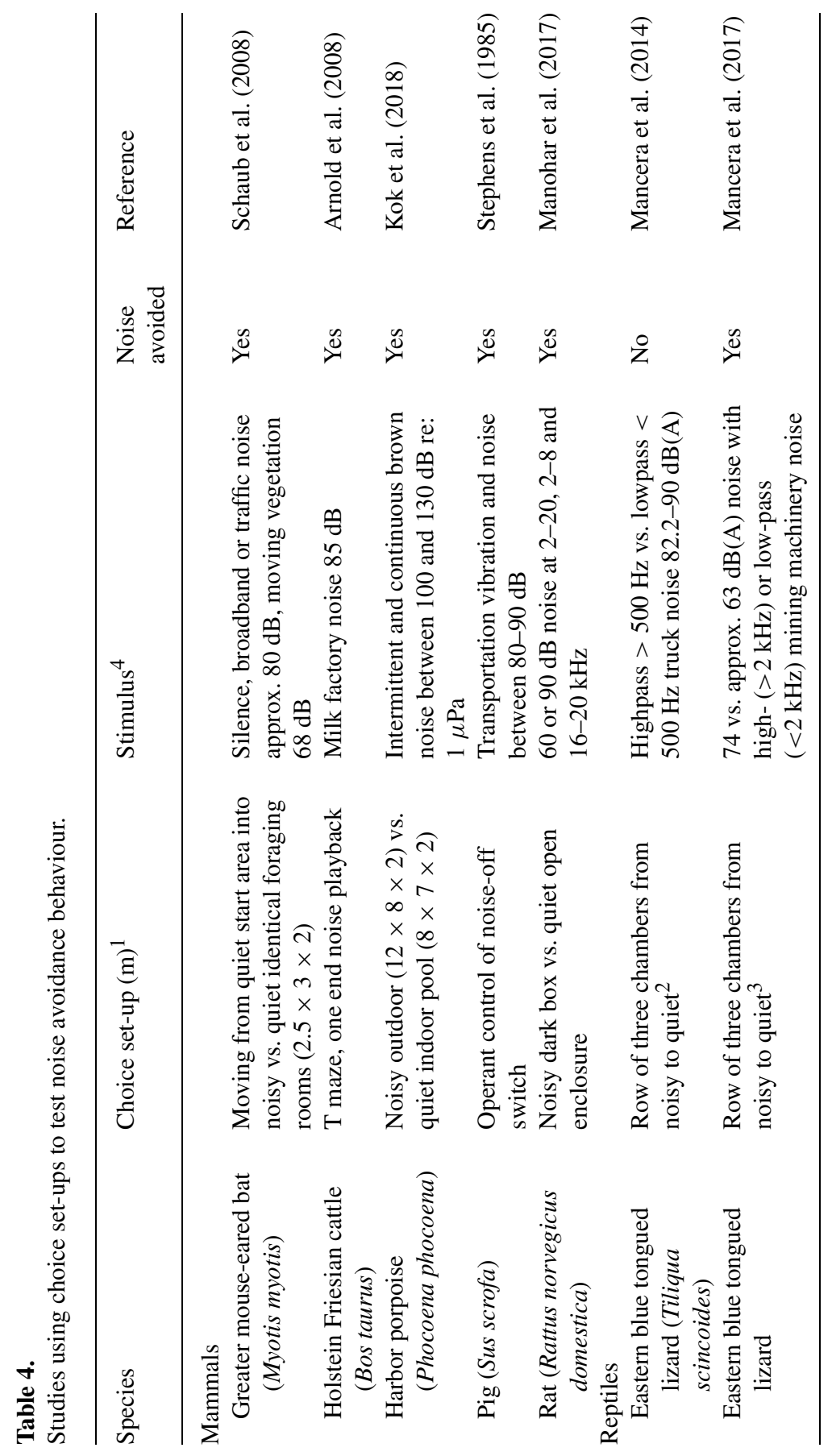




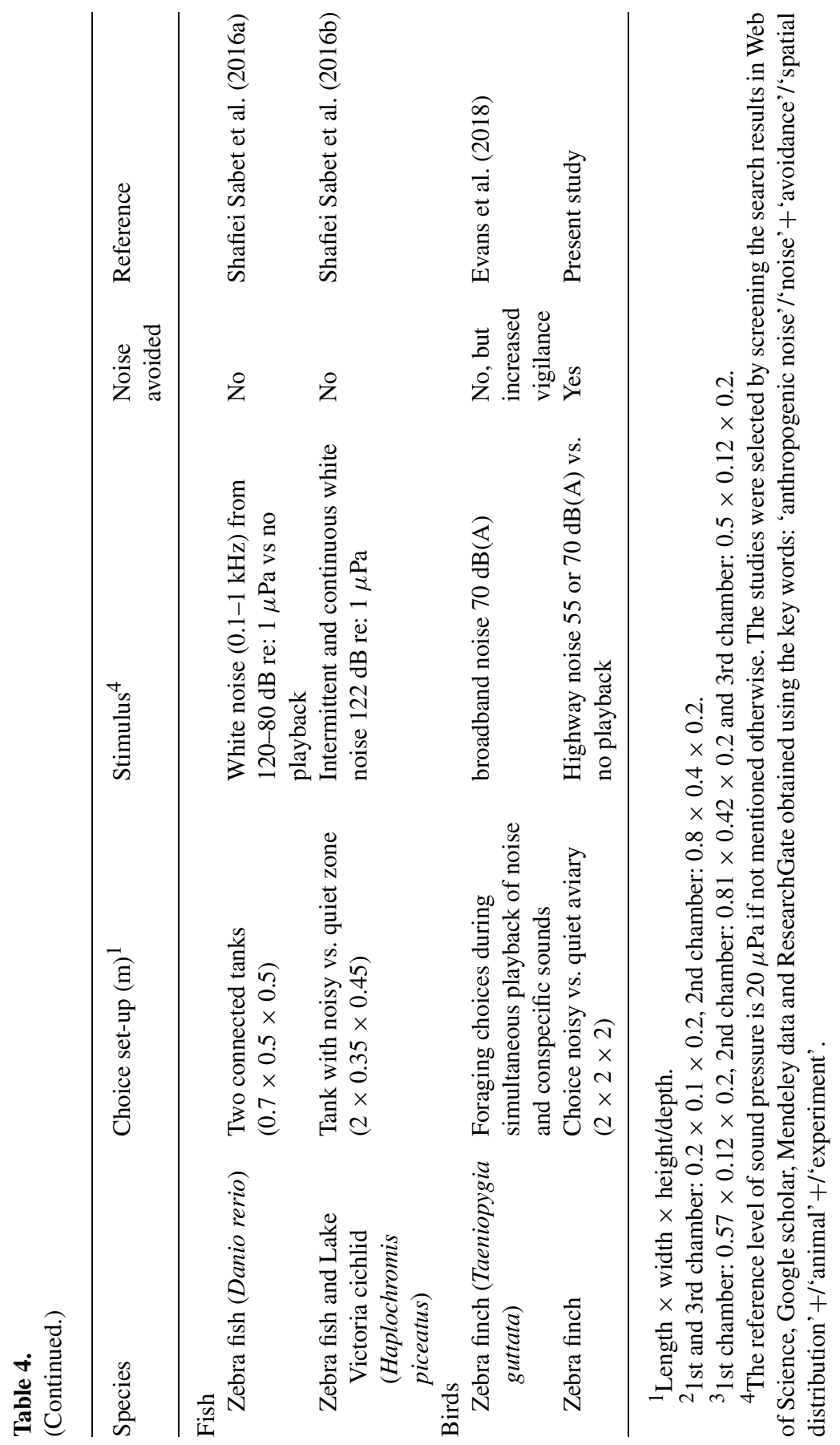


differing in noise levels. Bats hunted more in the relatively quieter chamber, but note that this bat species orientates on the sounds produced by their prey to locate them. This means that their behaviour can be both interpreted as attraction to the sounds of their prey (which were audible in the low level noise chamber but masked in the noisy chamber) or as an avoidance of the noise in the other chamber. Zebra finches are seed eaters and do not need to hear their prey. By using a comparable two-way choice design for the first time in a songbird allowed testing of whether noise avoidance per se guided birds' spatial behaviour. In the experiment, the tested birds avoided noisy conditions to move into a quieter space. This behaviour would confer an advantage outside the laboratory as complementary research in zebra finches has already shown that noise negatively impacts zebra finches: it increases vigilance reducing food uptake during foraging (Evans et al., 2018), affects intra-pair communication (Villain et al., 2016), offspring initial growth rates (Potvin \& MacDougall-Shackleton, 2015), reduces telomere length (DoradoCorrea et al., 2018) and affects song learning (Funabiki \& Funabiki, 2009; Potvin et al., 2016).

To date, only one other study also offered zebra finches a choice between quiet and noisy spaces: however, this was concurrent with access to food and playback of conspecific vocalisations (Evans et al. 2018). Birds showed increased vigilance in noise but little spatial sampling (most birds stayed in the first chamber they entered) and no preferences for quiet versus noisy cage compartments. This is different from the pronounced spatial choices observed in the birds in our study. However, the set-up used by Evans et al. (2018) was different in several aspects from our two-aviary study: a much smaller testing apparatus, individual rather than group testing of birds, manipulation of food availability, and simultaneous playbacks of noise and conspecifics. Any of these differences in design could be the reason why most birds in the set-up by Evans et al. (2018) only entered one compartment and stayed there. These differences stress the importance of potential context-dependency of active noise avoidance. Because zebra finches are highly social and engage in almost continuous acoustic exchange (Elie et al., 2011; L. Gill et al., 2015) when exploring the environment, behavioural decisions of the birds were likely not only driven by trying to avoid noise but also by their motivation to find food and/or join other birds after $2 \mathrm{~h}$ without food and company. In our set-up, the zebra finches were tested in groups of four and had ad libitum access to food, meaning that spatial preferences did 
not have to be weighed against food or company. To test whether social context indeed affects noise avoidance behaviour, our or comparable set-ups can be used in the future to investigate whether and how social companions and noisy conditions interact in affecting exploration and/or avoidance tendencies (Coleman \& Mellgren, 1994; Schuett \& Dall, 2009; Templeton et al., 2014).

Environmental noise can mask avian communication signals (Brumm \& Slabbekoorn, 2005; Halfwerk \& Slabbekoorn, 2015; Derryberry et al., 2016). In a highly social species like the zebra finch, this could affect group cohesion. Birds could become less explorative as not to lose visual contact if the exchange of information through vocal signals is impaired through masking (e.g. Villain et al., 2016). In the tests reported here, group cohesion was generally strong. In all three playback conditions birds spent around 93\% of their time in the group, suggesting that masking of contact calls is not likely to have influenced group cohesion in the experiments described here. These percentages may or may not look different for larger groups of birds or when housed in noisy conditions for longer than during the short tests presented here. Effects of noise on social behaviour and group structure could be investigated in the future with our aviary design by specifically monitoring calling behaviour and/or reinforcing it by playbacks (Schepers \& Proppe, 2017).

An aviary study in the laboratory cannot simulate how effects of noise exposure affect spatial preferences and noise-dependent distribution patterns in the field. Conversely, direct causality between ambient noise and the target species' behaviour is difficult to establish in the field where experimentally elevated sound levels could affect individuals directly, but inadvertently also affect other organisms in the ecosystem. This may yield indirect effects of noise on the target species via interactions with other species (Francis et al., 2009; Slabbekoorn \& Halfwerk, 2009; Hubert et al., 2018). Furthermore, factors like the reproductive stage or migratory status might affect responsiveness in the field and thus make it difficult to infer direct effects of noise (Ware et al., 2015). Laboratory studies provide a less natural environment but can keep potential confounds to a minimum, and can thus demonstrate a deterrent effect of traffic noise playback per se. Experiments, both in the field and in the laboratory, thus contribute to our understanding about the causal factors that explain the reduced species diversity and abundance in noisy versus quiet areas (Blickley et al., 2012; McClure et al., 2013). 


\subsection{Recording distance dependent response pattern}

In the experiment presented here, only the playback of the near- (but not the far-) distance highway noise affected how often and how long birds spent time in the different aviaries. These two types of highway noise differed substantially in amplitudes (approx. $15 \mathrm{~dB}(\mathrm{~A})$ ) and this seems the most likely reason why birds only avoided the aviary with playbacks of near-distance highway noise but not the playback of far-distance highway noise. It is important to note that the near-distance noise levels at around $70 \mathrm{~dB}(\mathrm{~A})$ are several orders of magnitude ( $\mathrm{dB}$ is a log scale) below the threshold where hearing cell damage occurs in zebra finches ( $>110 \mathrm{~dB}(\mathrm{~A})$; Funabiki \& Konishi 2003; Zevin et al., 2004) and well within the range that wild birds in urban and rural populations may experience (Wickham \& Riitters, 2003; Barber et al., 2011; Halfwerk et al., 2011b; Gil et al., 2015). This raises the question as to how easily birds can habituate to noisy conditions and whether birds habituated to high noise levels would have reacted differently, and/or whether birds found near busy roads have habituated to the traffic noise, or have no alternative habitat to choose.

The near- and far-distance highway noise recordings used in this study did not only differ in amplitude but also in their spectral characteristics. Overall, the far-distance highway noise has less energy at $1-4 \mathrm{kHz}$ than the neardistance noise. This is the range where zebra finches have the lowest hearing threshold. Therefore, moving from near-distance to far-distance noise, might perceptually release the birds from masking or noxious effects more than just the absolute reduction in amplitude. It is important to note that this difference in spectral characteristics is not an artefact of the method, but also applies to near and far distance locations in the vicinity of real highways. In the field, locations near and further from a highway also differ both in amplitude and spectral composition.

What our results unambiguously show is that the birds did not move away from the noisy conditions because they were unfamiliar with the sounds on the traffic noise recordings or were startled by it: although the far-distance noise was less loud than the near-distance recording, it was still around $55 \mathrm{~dB}(\mathrm{~A})$ which is above the level the WHO considers safe for human chronic exposure (see WHO Environmental Noise Guidelines, 2019). However, playbacks with these levels did not make the birds move to the quiet aviary. This makes neophobia or startle reactions unlikely explanations for our results but suggests that the louder near-distance noise (rather than any 
audible and unfamiliar sound) was being actively avoided. This avoidance response could prevent the negative impact of noisy conditions on acoustic communication, social decision making and foraging which have been reported from other experimental studies exposing zebra finches to noise playbacks (Swaddle et al., 2006; Swaddle \& Page, 2007; Villain et al., 2016; Evans et al., 2018).

Without being able to pinpoint down the lowest threshold of negative impact yet, the combined evidence from our and other studies suggests that for sound levels from $70 \mathrm{~dB}(\mathrm{~A})$ and higher ( $<15 \mathrm{~m}$ to the highway), traffic noise may affect communication, foraging, physiology and reproduction (Cynx et al., 1998; Potvin \& MacDougall-Shackleton, 2015; Potvin et al., 2016; Villain et al., 2016; Dorado-Correa et al., 2018). Wild birds of other species that were chronically exposed to anthropogenic noise were found to have altered glucocorticoid levels (Kleist et al., 2018; but see Crino et al., 2013), which in turn will raise energy demands (Jimeno et al., 2018). In combination with raised vigilance levels in noisy conditions (Quinn et al., 2006; Chan et al., 2010), this may further impact fitness prospects in noisy areas. Hence, avoiding noisy areas (given a choice) might well be beneficial for the birds and is in line with observed distribution patterns in the field in different songbird species (Parris \& Schneider, 2009; Arévalo \& Newhard, 2011; Goodwin \& Shriver, 2011; Herrera-Montes \& Aide, 2011; Proppe et al., 2013) and with avoidance patterns of (experimentally induced) noisy nest boxes (Kleist et al., 2017; Injaian et al., 2018a) or stopover sites near an experimental 'phantom road' (McClure et al., 2013).

The approach used with birds in this study could also be used in other taxa and independent of taxon specific modes of locomotion, which suggests it could be a suitable method for comparative work. Table 4 lists a number of species from other taxa that also suggest active preferences for quiet over noisy space. However, given the methodological differences and types of stimuli used, absence of such preferences in some of the examples is more difficult to interpret, for example in the fish studies, where active noise avoidance was not observed but where the complexity of sound directivity and propagation underwater, especially in small tanks makes it difficult to create linear noise gradients (Parvulescu, 1967; Akamatsu et al., 2002; Slabbekoorn, 2016). This adds to growing realisation that species, type, and level of anthropogenic noise exposure (and their fluctuations) need better characterisation (S. Gill et al., 2015). 


\subsection{Conclusions}

The birds in our test avoided space with near-distance, high amplitude traffic noise when given a choice at no cost of reduced access to food or increased risk of predation. This shows that, although additional (in)direct factors and interactions will contribute to patterns in the field, active behavioural avoidance of anthropogenic noise (above a certain threshold) will likely contribute to the distribution of birds along roads. We here tested only relatively shortterm exposure (hours) and short-term reactions, but the birds clearly showed that given a choice, they preferred quiet over noisy, when above a particular threshold. Future work will have to test how habituation may or may not reduce such avoidance behaviour. Traffic noise is affecting more and more areas on our planet. The chronic noise exposure for animals living in such areas may detrimentally affect them, but may also make animals avoid settling in such areas in the first place. It is thus important to keep in mind that sound can reduce the value of an area of otherwise suitable animal habitat immediately up to quite some distance away from a given noise source. Assessing the distances and thresholds at which different species are affected might be an important aspect to consider for better understanding traffic noise impact and appropriate policy making.

\section{References}

Akamatsu, T., Okumura, T., Novarini, N. \& Yan, H.Y. (2002). Empirical refinements applicable to the recording of fish sounds in small tanks. - J. Acoust. Soc. Am. 112: 3073-3082.

Arévalo, J.E. \& Newhard, K. (2011). Traffic noise affects forest bird species in a protected tropical forest. — Rev. Biol. Trop. 59: 969-980.

Audacity Team (2019). Audacity(R): free audio editor and recorder. — Available online at www.audacityteam.org.

Barber, J.R., Burdett, C.L., Reed, S.E., Warner, K.A., Formichella, C., Crooks, K.R., Theobald, D.M. \& Fristrup, K.M. (2011). Anthropogenic noise exposure in protected natural areas: estimating the scale of ecological consequences. — Landsc. Ecol. 26: 12811295.

Barber, J.R., Crooks, K.R. \& Fristrup, K.M. (2010). The costs of chronic noise exposure for terrestrial organisms. - Trends Ecol. Evol. 25: 180-189.

Basner, M., Babisch, W., Davis, A., Brink, M., Clark, C., Janssen, S. \& Stansfeld, S. (2014). Auditory and non-auditory effects of noise on health. — Lancet 383: 1325-1332.

Bayne, E.M., Habib, L. \& Boutin, S. (2008). Impacts of chronic anthropogenic noise from energy-sector activity on abundance of songbirds in the boreal forest. - Conserv. Biol. 22: 1186-1193. 
Benítez-López, A., Alkemade, R. \& Verweij, P.A. (2010). The impacts of roads and other infrastructure on mammal and bird populations: a meta-analysis. - Biol. Conserv. 143: 1307-1316.

Bent, A.M., Ings, T.C. \& Mowles, S.L. (2018). Anthropogenic noise disrupts mate searching in Gryllus bimaculatus. — Behav. Ecol. 29: 1271-1277.

Blickley, J.L., Blackwood, D. \& Patricelli, G.L. (2012). Experimental evidence for the effects of chronic anthropogenic noise on abundance of greater sage-grouse at leks. - Conserv. Biol. 26: 461-471.

Boersma, P. \& Weenink, D. (2019). Praat: doing phonetics by computer. — Available online at http://www.fon.hum.uva.nl/praat/.

Brumm, H. \& Slabbekoorn, H. (2005). Acoustic communication in noise. - Adv. Stud. Behav. 35: 151-209.

Chan, A.A.Y.-H., Giraldo-Perez, P., Smith, S. \& Blumstein, D.T. (2010). Anthropogenic noise affects risk assessment and attention: the distracted prey hypothesis. — Biol. Lett. 6: 458461.

Coleman, S.L. \& Mellgren, R.L. (1994). Neophobia when feeding alone or in flocks in zebra finches, Taeniopygia guttata. — Anim. Behav. 48: 903-907.

Crino, O.L., Johnson, E.E., Blickley, J.L., Patricelli, G.L. \& Breuner, C.W. (2013). Effects of experimentally elevated traffic noise on nestling white-crowned sparrow stress physiology, immune function and life history. - J. Exp. Biol. 216: 2055-2062.

Cynx, J., Lewis, R., Tavel, B. \& Tse, H. (1998). Amplitude regulation of vocalizations in noise by a songbird, Taeniopygia guttata. - Anim. Behav. 56: 107-113.

Derryberry, E.P., Danner, R.M., Danner, J.E., Derryberry, G.E., Phillips, J.N., Lipshutz, S.E., Gentry, K. \& Luther, D.A. (2016). Patterns of song across natural and anthropogenic soundscapes suggest that white-crowned sparrows minimize acoustic masking and maximize signal content. — PLoS ONE 11: e0154456.

Dorado-Correa, A.M., Zollinger, S.A., Heidinger, B. \& Brumm, H. (2018). Timing matters: traffic noise accelerates telomere loss rate differently across developmental stages. Front. Zool. 15: 29.

Elie, J.E., Soula, H.A., Mathevon, N. \& Vignal, C. (2011). Dynamics of communal vocalizations in a social songbird, the zebra finch (Taeniopygia guttata). - J. Acoust. Soc. Am. 129: 4037-4046.

Evans, J.C., Dall, S.R.X. \& Kight, C.R. (2018). Effects of ambient noise on zebra finch vigilance and foraging efficiency. — PLoS ONE 13: e0209471.

Francis, C.D., Ortega, C.P. \& Cruz, A. (2009). Noise pollution changes avian communities and species interactions. - Curr. Biol. 19: 1415-1419.

Friard, O. \& Gamba, M. (2016). BORIS: a free, versatile open-source event-logging software for video/audio coding and live observations. — Methods Ecol. Evol. 7: 1325-1330.

Funabiki, Y. \& Funabiki, K. (2009). Factors limiting song acquisition in adult zebra finches. — Dev. Neurobiol. 69: 752-759.

Funabiki, Y. \& Konishi, M. (2003). Long memory in song learning by zebra finches. J. Neurosci. 23: 6928-6935. 
Gil, D., Honarmand, M., Pascual, J., Pérez-Mena, E. \& Macías Garcia, C. (2015). Birds living near airports advance their dawn chorus and reduce overlap with aircraft noise. - Behav. Ecol. 26: 435-443.

Gill, L.F., Goymann, W., Ter Maat, A. \& Gahr, M. (2015). Patterns of call communication between group-housed zebra finches change during the breeding cycle. - eLife 4: e07770.

Gill, S.A., Job, J.R., Myers, K., Naghshineh, K. \& Vonhof, M.J. (2015). Toward a broader characterization of anthropogenic noise and its effects on wildlife. - Behav. Ecol. 26: 328-333.

Goodwin, S.E. \& Shriver, W.G. (2011). Effects of traffic noise on occupancy patterns of forest birds. - Conserv. Biol. 25: 406-411.

Grade, A.M. \& Sieving, K.E. (2016). When the birds go unheard: highway noise disrupts information transfer between bird species. — Biol. Lett. 12: 20160113.

Habib, L., Bayne, E.M. \& Boutin, S. (2007). Chronic industrial noise affects pairing success and age structure of ovenbirds Seiurus aurocapilla. — J. Appl. Ecol. 44: 176-184.

Halfwerk, W., Bot, S., Buikx, J., van der Velde, M., Komdeur, J., ten Cate, C. \& Slabbekoorn, H. (2011a). Low-frequency songs lose their potency in noisy urban conditions. - Proc. Natl. Acad. Sci. USA 108: 14549-14554.

Halfwerk, W., Holleman, L.J.M., Lessells, Ck.M. \& Slabbekoorn, H. (2011b). Negative impact of traffic noise on avian reproductive success. — J. Appl. Ecol. 48: 210-219.

Halfwerk, W. \& Slabbekoorn, H. (2015). Pollution going multimodal: the complex impact of the human-altered sensory environment on animal perception and performance. - Biol. Lett. 11: 20141051.

Herrera-Montes, M.I. \& Aide, T.M. (2011). Impacts of traffic noise on anuran and bird communities. - Urban Ecosyst. 14: 415-427.

Hubert, J., Campbell, J., van der Beek, J.G., den Haan, M.F., Verhave, R., Verkade, L.S. \& Slabbekoorn, H. (2018). Effects of broadband sound exposure on the interaction between foraging crab and shrimp — a field study. — Environ. Pollut. 243: 1923-1929.

Huet des Aunay, G., Slabbekoorn, H., Nagle, L., Passas, F., Nicolas, P. \& Draganoiu, T.I. (2014). Urban noise undermines female sexual preferences for low-frequency songs in domestic canaries. - Anim. Behav. 87: 67-75.

Iglesias Merchan, C., Diaz-Balteiro, L. \& Soliño, M. (2014). Noise pollution in national parks: soundscape and economic valuation. — Landsc. Urban Plan. 123: 1-9.

Injaian, A.S., Gonzalez-Gomez, P.L., Taff, C.C., Bird, A.K., Ziur, A.D., Patricelli, G.L., Haussmann, M.F. \& Wingfield, J.C. (2019). Traffic noise exposure alters nestling physiology and telomere attrition through direct, but not maternal, effects in a free-living bird. — Gen. Comp. Endocrinol. 276: 14-21.

Injaian, A.S., Poon, L.Y. \& Patricelli, G.L. (2018a). Effects of experimental anthropogenic noise on avian settlement patterns and reproductive success. - Behav. Ecol. 29: 11811189 .

Injaian, A.S., Taff, C.C. \& Patricelli, G.L. (2018b). Experimental anthropogenic noise impacts avian parental behaviour, nestling growth and nestling oxidative stress. - Anim. Behav. 136: 31-39. 
Injaian, A.S., Taff, C.C., Pearson, K.L., Gin, M.M.Y., Patricelli, G.L. \& Vitousek, M.N. (2018c). Effects of experimental chronic traffic noise exposure on adult and nestling corticosterone levels, and nestling body condition in a free-living bird. - Horm. Behav. 106: 19-27.

Jack, J., Rytwinski, T., Fahrig, L. \& Francis, C.M. (2015). Influence of traffic mortality on forest bird abundance. - Biodivers. Conserv. 24: 1507-1529.

Jimeno, B., Hau, M. \& Verhulst, S. (2018). Corticosterone levels reflect variation in metabolic rate, independent of 'stress'. - Sci. Rep. 8: 13020.

Kight, C.R., Saha, M.S. \& Swaddle, J.P. (2012). Anthropogenic noise is associated with reductions in the productivity of breeding eastern bluebirds (Sialia sialis). - Ecol. Appl. 22: 1989-1996.

Kight, C.R. \& Swaddle, J.P. (2011). How and why environmental noise impacts animals: an integrative, mechanistic review. - Ecol. Lett. 14: 1052-1061.

Kleist, N.J., Guralnick, R.P., Cruz, A. \& Francis, C.D. (2017). Sound settlement: noise surpasses land cover in explaining breeding habitat selection of secondary cavity-nesting birds. — Ecol. Appl. 27: 260-273.

Kleist, N.J., Guralnick, R.P., Cruz, A., Lowry, C.A. \& Francis, C.D. (2018). Chronic anthropogenic noise disrupts glucocorticoid signaling and has multiple effects on fitness in an avian community. — Proc. Natl. Acad. Sci. USA 115: E648-E657.

Luther, D.A., Phillips, J. \& Derryberry, E.P. (2016). Not so sexy in the city: urban birds adjust songs to noise but compromise vocal performance. — Behav. Ecol. 27: 332-340.

McClure, C.J.W., Ware, H.E., Carlisle, J., Kaltenecker, G. \& Barber, J.R. (2013). An experimental investigation into the effects of traffic noise on distributions of birds: avoiding the phantom road. — Proc. Roy. Soc. Lond. B: Biol. Sci. 280: 20132290.

Mennitt, D., Fristrup, K. \& Nelson, L. (2015). A spatially explicit estimate of environmental noise exposure in the contiguous United States. - J. Acoust. Soc. Am. 137: 2339-2340.

Merchant, N.D., Fristrup, K.M., Johnson, M.P., Tyack, P.L., Witt, M.J., Blondel, P. \& Parks, S.E. (2015). Measuring acoustic habitats. — Methods Ecol. Evol. 6: 257-265.

Mönkkönen, M. \& Forsman, J.T. (2002). Heterospecific attraction among forest birds: a review. - Ornithol. Sci. 1: 41-51.

Naguib, M. (2013). Living in a noisy world: indirect effects of noise on animal communication. - Behaviour 150: 1069-1084.

Newport, J., Shorthouse, D.J. \& Manning, A.D. (2014). The effects of light and noise from urban development on biodiversity: implications for protected areas in Australia. - Ecol. Manag. Restor. 15: 204-214.

Nugent, C., Blanes, N., Fons, J., de la Maza, M.S., Ramos, J.M., Domingues, F., van Beek, A. \& Houthuijs, D. (2014). Noise in Europe 2014. — Publications Office of the European Union, Luxembourg.

Parks, S.E., Johnson, M., Nowacek, D. \& Tyack, P.L. (2011). Individual right whales call louder in increased environmental noise. - Biol. Lett. 7: 33-35.

Parris, K.M. \& Schneider, A. (2009). Impacts of traffic noise and traffic volume on birds of roadside habitats. - Ecol. Soc. 14: 29. 
Parvulescu, A. (1967). The acoustics of small tanks. — In: Marine bioacoustics. Pergamon Press, Oxford, p. 7-13.

Potvin, D.A. \& MacDougall-Shackleton, S.A. (2015). Traffic noise affects embryo mortality and nestling growth rates in captive zebra finches. - J. Exp. Zool. Part A: Ecol. Genet. Physiol. 323: 722-730.

Potvin, D.A., Curcio, M.T., Swaddle, J.P. \& MacDougall-Shackleton, S.A. (2016). Experimental exposure to urban and pink noise affects brain development and song learning in zebra finches (Taenopygia guttata). - PeerJ 4: e2287.

Proppe, D.S., Sturdy, C.B. \& St. Clair, C.C. (2013). Anthropogenic noise decreases urban songbird diversity and may contribute to homogenization. - Glob. Chang. Biol. 19: 10751084.

Quinn, J., Whittingham, M., Butler, S. \& Cresswell, W. (2006). Noise, predation risk compensation and vigilance in the chaffinch Fringilla coelebs. - J. Avian Biol. 37: 601-608.

R Core Team (2019). R: a language and environment for statistical computing. — R Foundation for Statistical Computing, Vienna.

Reijnen, R., Foppen, R. \& Meeuwsen, H. (1996). The effects of traffic on the density of breeding birds in Dutch agricultural grasslands. - Biol. Conserv. 75: 255-260.

Schaub, A., Ostwald, J. \& Siemers, B.M. (2008). Foraging bats avoid noise. - J. Exp. Biol. 211: 3174-3180.

Schepers, M.J. \& Proppe, D.S. (2017). Song playback increases songbird density near low to moderate use roads. - Behav. Ecol. 28: 123-130.

Schuett, W. \& Dall, S.R.X. (2009). Sex differences, social context and personality in zebra finches, Taeniopygia guttata. - Anim. Behav. 77: 1041-1050.

Shannon, G., McKenna, M.F., Angeloni, L.M., Crooks, K.R., Fristrup, K.M., Brown, E., Warner, K.A., Nelson, M.D., White, C., Briggs, J., McFarland, S. \& Wittemyer, G. (2016). A synthesis of two decades of research documenting the effects of noise on wildlife. Biol. Rev. 91: 982-1005.

Siemers, B.M. \& Schaub, A. (2011). Hunting at the highway: traffic noise reduces foraging efficiency in acoustic predators. — Proc. Roy. Soc. Lond. B: Biol. Sci. 278: 1646-1652.

Slabbekoorn, H. (2016). Aiming for progress in understanding underwater noise impact on fish: complementary need for indoor and outdoor studies. - Adv. Exp. Med. Biol. 875: 1057-1065.

Slabbekoorn, H. \& Halfwerk, W. (2009). Behavioural ecology: noise annoys at community level. - Curr. Biol. 19: R693-R695.

Sokal, R.R. \& Rohlf, F.J. (1995). Biometry: the principles and practice of statistics in biological research, 3rd edn. - W.H. Freeman, New York, NY.

Summers, P.D., Cunnington, G.M. \& Fahrig, L. (2011). Are the negative effects of roads on breeding birds caused by traffic noise? - J. Appl. Ecol. 48: 1527-1534.

Swaddle, J.P., McBride, L. \& Malhotra, S. (2006). Female zebra finches prefer unfamiliar males but not when watching noninteractive video. - Anim. Behav. 72: 161-167.

Swaddle, J.P. \& Page, L.C. (2007). High levels of environmental noise erode pair preferences in zebra finches: implications for noise pollution. — Anim. Behav. 74: 363-368. 
Tachibana, R.O., Takahasi, M., Hessler, N.A. \& Okanoya, K. (2017). Maturation-dependent control of vocal temporal plasticity in a songbird. — Dev. Neurobiol. 77: 995-1006.

Templeton, C.N., Laland, K.N. \& Boogert, N.J. (2014). Does song complexity correlate with problem-solving performance in flocks of zebra finches?. - Anim. Behav. 92: 63-71.

Tennessen, J.B., Parks, S.E. \& Langkilde, T. (2014). Traffic noise causes physiological stress and impairs breeding migration behaviour in frogs. - Conserv. Physiol. 2: cou032.

Tumer, E.C. \& Brainard, M.S. (2007). Performance variability enables adaptive plasticity of “crystallized" adult birdsong. — Nature 450: 1240-1244.

Vasconcelos, R.O., Amorim, M.C.P. \& Ladich, F. (2007). Effects of ship noise on the detectability of communication signals in the Lusitanian toadfish. - J. Exp. Biol. 210: 2104-2112.

Villain, A.S., Fernandez, M.S.A., Bouchut, C., Soula, H.A. \& Vignal, C. (2016). Songbird mates change their call structure and intrapair communication at the nest in response to environmental noise. - Anim. Behav. 116: 113-129.

Voellmy, I.K., Purser, J., Flynn, D., Kennedy, P., Simpson, S.D. \& Radford, A.N. (2014). Acoustic noise reduces foraging success in two sympatric fish species via different mechanisms. - Anim. Behav. 89: 191-198.

Wale, M.A., Simpson, S.D. \& Radford, A.N. (2013). Noise negatively affects foraging and antipredator behaviour in shore crabs. - Anim. Behav. 86: 111-118.

Ware, H.E., McClure, C.J.W., Carlisle, J.D. \& Barber, J.R. (2015). A phantom road experiment reveals traffic noise is an invisible source of habitat degradation. - Proc. Natl. Acad. Sci. USA 112: 12105-12109.

Wickham, J.D. \& Riitters, K.H. (2003). How far to the nearest road? — Front. Ecol. Environ. 1: $125-129$.

Winger, B.M., Weeks, B.C., Farnsworth, A., Jones, A.W., Hennen, M. \& Willard, D.E. (2019). Nocturnal flight-calling behaviour predicts vulnerability to artificial light in migratory birds. — Proc. Roy. Soc. Lond. B: Biol. Sci. 286: 20190364.

World Health Organization (2017). Burden of disease from environmental noise: quantification of healthy life years lost in Europe. - World Health Organization (WHO) Regional Office for Europe, Copenhagen.

World Health Organization (2019). Environmental noise guidelines. - Available online at http://www.euro.who.int/en/health-topics/environment-and-health/noise/environmentalnoise-guidelines-for-the-european-region.

Wright, A.J., Soto, N.A., Baldwin, A.L., Bateson, M., Beale, C.M., Clark, C., Deak, T., Edwards, E.F., Fernández, A., Godinho, A., Hatch, L.T., Kakuschke, A., Lusseau, D., Martineau, D., Romero, M.L., Weilgart, L.S., Wintle, B.A., Notarbartolo-di-Sciara, G. \& Martin, V. (2007). Anthropogenic noise as a stressor in animals: a multidisciplinary perspective. - Int. J. Comp. Psychol. 20: 250-273.

Zann, R.A. (1996). The zebra finch: a synthesis of field and laboratory studies. — Oxford University Press, Oxford.

Zevin, J.D., Seidenberg, M.S. \& Bottjer, S.W. (2004). Limits on reacquisition of song in adult zebra finches exposed to white noise. - J. Neurosci. 24: 5849-5862. 


\section{Appendix}

\section{Formula used to calculate $d B F S$}

$\mathrm{dB}$ to full scale ( $\mathrm{dB}$ FS) conversion formula used in editing stimuli (MS line 178) and making Figures 2 and 3.

Step 1: Relative amplitude to full scale $(0,1]=$ Positive Sample/maximal positive value or Negative sample/minimal negative value

Step 2: Relative $\mathrm{dB}$ to full scale $(-\infty, 0]=20 * \log _{10}$ (Relative amplitude to full scale)

\section{Table A1.}

Recording locations of the highway noise stimuli.

\begin{tabular}{lll}
\hline File & Location & Coordinates \\
\hline Near-Site1 A4 & Vlietland & $52^{\circ} 06^{\prime} 12.5^{\prime \prime} \mathrm{N} 4^{\circ} 26^{\prime} 28.1^{\prime \prime} \mathrm{E}$ \\
Far-Site1 A4 & Vlietland & $52^{\circ} 06^{\prime} 12.5^{\prime \prime} \mathrm{N} 4^{\circ} 26^{\prime} 28.1^{\prime \prime} \mathrm{E}$ \\
Near-Site2 A4 & Polderpark Cronesteyn & $52^{\circ} 08^{\prime} 12.9^{\prime \prime} \mathrm{N} 4^{\circ} 30^{\prime} 07.5^{\prime \prime} \mathrm{E}$ \\
Far-Site2 A4 & Polderpark Cronesteyn & $52^{\circ} 08^{\prime} 12.9^{\prime \prime} \mathrm{N} 4^{\circ} 30^{\prime} 07.5^{\prime \prime} \mathrm{E}$ \\
Near-Site3 A44 & Oegstgeest & $52^{\circ} 10^{\prime} 34.2^{\prime \prime} \mathrm{N} 4^{\circ} 27^{\prime} 33.4^{\prime \prime} \mathrm{E}$ \\
Far-Site3 A44 & Oegstgeest & $52^{\circ} 10^{\prime} 34.2^{\prime \prime} \mathrm{N} 4^{\circ} 27^{\prime} 33.4^{\prime \prime} \mathrm{E}$ \\
Near-Site4 A44 & Park Landskroon & $52^{\circ} 10^{\prime} 22.7^{\prime \prime} \mathrm{N} 4^{\circ} 27^{\prime} 07.6^{\prime \prime} \mathrm{E}$ \\
Far-Site4 A44 & Park Landskroon & $52^{\circ} 10^{\prime} 22.7^{\prime \prime} \mathrm{N} 4^{\circ} 27^{\prime} 07.6^{\prime \prime} \mathrm{E}$ \\
\hline
\end{tabular}



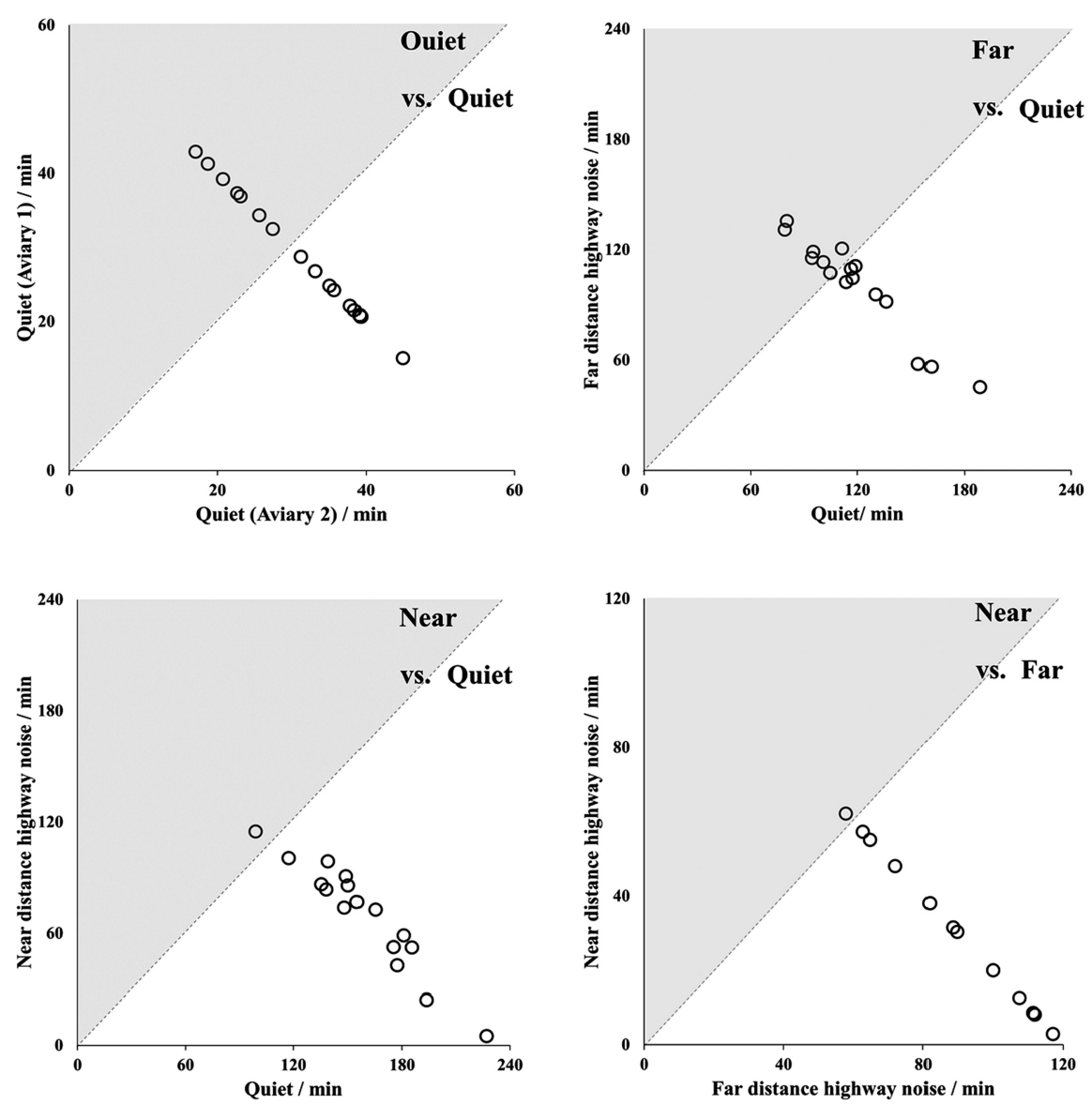

Figure A1. Total time each group of birds spent in either of the two aviaries during different playback treatments. (a) Quiet vs. quiet during pre-playback ( $N=16$ groups, maximal time spent $=60 \mathrm{~min})$, (b) far vs. quiet $(N=16$ groups, maximal time spent $=240 \mathrm{~min}$ ), (c) near vs. quiet $(N=16$ groups, maximal time spent $=240 \mathrm{~min})$ and $(\mathrm{d})$ near vs. far during simultaneous playback 3 ( $N=12$ groups, maximal time spent $=120 \mathrm{~min}$ ). Each dot is one tested group. Dots in (b) and (c) are jittered for visualization. Dots in the grey area show groups of birds that spent more time in the relatively noisier aviary while dots in the white area show birds spent more time in the relatively more quiet aviary (with the exception of plot a) of the pre-playback condition, where the colours symbol the two aviaries as there was no playback). The grey and white area are separated by the $y=x$ line (all dots would be on this line if birds showed an equal preference). 